\title{
URBAN BIO CLIMATIC DISCOMFORT INDEX OF RESIDENTS IN CALABAR METROPOLIS CROSS RIVER STATE \\ BEING TETFFUND RESEARCH GRANT STUDY UNDER TAKEN
}

\author{
JOSEPH IBU UPLA(Ph.D) $)^{\mathrm{a}}$ DEMOT NJAGU BISONG(Ph.D) ${ }^{\mathrm{b}} *$ \\ a okwilliams55@gmail.com \\ Department of Geography Cross River State College of Education, Akamkpa \\ Department of Geography Cross River State College of Education, Akamkpa
}

\begin{abstract}
This study aims at investigating the urban bioclimatic discomfort index of residents .in Calabar. The problem statement derives from the identification of residents health implication of the Urban Heat Island (UH1) impact on residents based on investigation carried in other similar cities of the world. For effective data collection, landscape /landcover types would be identified and categorized. Equally, residential areas were designated into city locales or clusters on the basis of' planning, architectural design and mostly contiguity. Population categories employed would be both biophysical and socio cultural. Instruments for data collection would be selected in line with attributes of the population. Thus, questionnaire instruments would be used to elicit information from residents on the basis of their sensitivity to the heat discomfort incidence. Also, heat variation according to landscape/landcover categories would. be detected through the use of thermometers mounted on improvised Stevenson Screen stationed at purposively sampled locations. Global positioning system coordinates recording would be taken for each point. The data collected was analyzed based on nonparametric and parametric statistics. The findings aim at identified the differences in heat sensitivity among residents according to age, two hypothesis were tested using the parameter of age. Hypothesis 1 analysed heat sensitivity within age brackets 6-20 years of age. Hypothesis11 analysed heat sensitivity within the age brackets 21-50 years of age. Following the results the null hypothesis was accepted for hypothesis 1 indicating that there is no significant difference in the heat densitivity index for age category 6-20 years of age. While for hypothesis II the null hypothesis was upheld indicating that there is a significant variation in the heat densitivity among the age category $21-50$ years.
\end{abstract}

Keyword: Urban Bioclimatic, Discomfort index , Residents 


\section{INTRODUCTION}

Urban areas have clearly been designated as areas with unique climatic regimes. This uniqueness is clearly exemplified in the parameters of temperature, rainfall, wind, sunshine and so on. The peculiarity of the weather cycles of these elements confer on the urban landscape a microclimate mosaic which manifest on temporal and spatial scales. On spatial scale is the urban micro climatic mosaics which vary according to landscape/Landcover characteristics, anthropogenic activity type and urban architectural design. Temporally, the weather regimes is clearly differentiated in its thermodynamic and humidity patterns between the seasonal cycles. A manifest aspect of the urban climate peculiarity is the urban heat Island phenomenon which relates to the differences in the heat pattern between the urban inner city area and the corresponding temperature of the urban periphery or suburbia. The urban heat incidence has been severally investigated and documented in literature for several cities of the developed world. On the contrary, in cities of the developing regions less progress has been made in this direction. Available evidence of this urban heat differential provided that there is an average heat difference of $4.5^{\circ} \mathrm{c}$ between inner city and the urban periphery of about $4.5^{\circ} \mathrm{c}$

Ifatimehine (2002) in his study of urban heat island of Lokoja, Reported that the heat difference between the inner city and its surrounding was about $5.0^{\circ} \mathrm{c}$. Numerous Such reports have been provided by investigations carried on cities of developing regions of different sizes (Picket et al 2001, Zhao and Wag, 2002, Bonan 2002, Cunningham and Siago 2002, Yoshikaido and Tsushid 1996).

Accordingly, it has also been clearly investigated and reported that the heat intensity scope is a function of the city size and the urban Landscape Morphology. Essentially, the urban heat incidence forms a canopy of hot air that separates the temperature of the inner city from that of the country side. This is called the urban heat dome (Marsh and Grossa 2002) Urban heat development and its attendant climatic anomalies have significant health implications on urban population. An important aspect of UHI impact on human health is the urban heat discomfort index which refers to the impact of heat on human physiological and psychosomatic elements.

The heat discomfort index incidence has also been variously investigated in the literature. Several models of the heat discomfort index have been provided by scholars in the field. Balogun and Balogun (2014) in their study of urban heat island bioclimatic conditions in Akure, Nigeria, Adopted the thermohydrogrometic index (THI) model. The THI model uses temperature and humidity data in the explanation of bioclimatic' index. This bioclimatic index, is used in the explanation of human discomfort. This model finds its appropriate application in Calabar being in the tropical regions of the world. Urban heat development and its corresponding condition is exacerbated by a combination of factors in the city of Calabar due to the sheer essence of its tropical location, the burgeoning population of the city and the current phenomenon of global warming and climate change. This scenario provides the drive for this research intention.

\section{Executive summary}

Urban heat warming constitutes a significant incidence of urban micro climates regimes in most cities of the world as well as in Calabar Nigeria. Urban heat island incidence has received a prodigeous degree of attention by environmental managers in recent times.

The increased attention is premised on the awareness of the general ecological impact of the UHI urban locale. With particular reference to the city of Calabar residents reports of the menace of this incidence is worthy of note.

This research is envisaged to particularly investigate the bio-climatic discomfort index of residents in the study area for purposes of urban environmental health planning and other related spheres of urban planning. Inline with the Broadview aim of the study stated above, the inherent specific objective is to:

Investigates the heat stress susceptibility of individual of various age categories.

The significance of the study is multifaceted:

- It is a pre-requisite for urban environmental health planning 
- Urban planning generally in such area as urban layout design, urban architectural design and urban residential planning will be equally favoured by the findings of the proposed research and

- Urban heat mitigation and adaptation by residents and urban planners will be greatly enhanced by the results of these findings.

Accordingly, the research is a field survey design based on insitu data collection from the field involving both biophysical and socio-cultural data. The research population are of two categories based on Biophysical and sociocultural parameters. Similarly, multi-stage sampling is employed involving purposive samples techniques for selection of landscape types, stratified sampling for residents, categorization and random sampling for drawing of representing samples from residents categories.

Data analysis will involve employment of parametric based on analysis of variance (ANOVA)statistics. The study will ascertain the heat discomfort pattern among the residents according to age. The recommendation will be in line with the findings derived from the study. In the heat pattern between the urban inner city area and the corresponding temperature of the urban periphery or suburbia. The urban heat incidence has been severally investigated and documented in literature for several cities of the developed world. On the contrary, in cities of the developing regions less progress has been made in this direction. Available evidence of this urban heat differential provided that there is an average heat difference of $4.5^{\circ} \mathrm{c}$ between inner city and the urban periphery of about $4.5^{\circ} \mathrm{c}$.

Ifatimehine (2002) in his study of urban heat island of Lokoja, Reported that the heat difference between the inner city and its surrounding was about $5.0^{\circ} \mathrm{c}$. Numerous Such reports have been provided by investigations carried on cities of developing regions of different sizes (Picket et al 2001, Zhao and Wag, 2002, Bonan 2002, Cunningham and Siago 2002, Yoshikaido and Tsushid 1996).

Accordingly, it has also been clearly investigated and reported that the heat intensity scope is a function of the city size and the urban Landscape Morphology. Essentially, the urban heat incidence forms a canopy -of hot air that separates the temperature of the inner city from that of the country side. This is called the urban heat dome (Marsh and Grossa 2002). Urban Heat development and its attendant climatic anomalies have significant health implications on urban population. An important aspect of the UHI impact on human health is the urban heat discomfort: index which refers to the impact of heat on human physiological and psychosomatic elements.

The heat discomfort index incidence has also been variously investigated in the literature. Several models of the heat discomfort index have been provided by scholars in- the field. Balogu and Balogun (2014) in their study of urban heat island bioclimatic conditions in Akure, Nigeria, Adopted the thermohydrogrometic index (THI) model. The THI model uses temperature and humidity data in the explanation of bioclimatic index. This bioclimatic index is used in the explanation of human discomfort in beings (Toy et al 2007). This model finds its appropriate application in Calabar being in the tropical regions of the world. Urban heat development and its corresponding condition is exacerbated by a combination of factors in the city of Calabar due to the sheer essence of its tropical location, the burgeoning population of the city and the current phenomenon of global warming and climate change. This scenario provides the drive for this research intention.

\section{Statement of the problem}

Urban environmental Management requires a whole lot of attention. It demands attention in its the rapidly changing biophysical parameters such as changes in the Landscape Albedo due to the transformation in urban land cover, deforestation of urban vegetation, building compaction of urban architectural design and lots more.

Socioculturally, the urban ecology .presents a maze of anthropogenically derived images of existence namely urban population agglomeration, (Overcrowding), traffic hold ups, urban noise, urban heat stress, urban accommodation problem and so on. The combination of these scenarios make urban living a hearth of stress and distress which impinge heavily on the health of its residents. Urban development's planners require a great deal of information on the precursors of these problems in order to proffer appropriate solutions to 
them. Much progress in research has been made in this direction in cities of developed regions whereas in cities of developing regions such as Calabar, information is at best scanty.

Urban bioclimatic index is one area of urban environmental health problems that demands urgent attention due to the rising temperature of urban areas caused by climate change, global warming and urban anthropogenic activities that instigate the heat incidence within the urban city domain. Several variants of this discomfort index phenomenon requires vigorous investigation due to their far reaching health effects.

Several parameters of human physiological, psychosomatic and environmental conditions that instigate the heat discomfort index demand clear- cut investigation. Interesting insights have been provided from studies carried out in other parts of the world concerning the relationship between heat index and the index of skin temperature, heat acclamation of women, body size and individual response to heat. The numerous combination of parameters remain more or less unexplored which provides the imperative for this research proposal.

\section{Aims and objectives of the research}

\section{- Research Aims:}

The overall objectives of this proposed research study is to investigate the human bioclimatic discomfort index of city residents.

- Specific Objectives: This study focuses on a single parameter and so the objective is inline with the overall aim, that is to investigate the heat stress susceptibility of individual of various age categories.

Note: inline with the scope of this study one parameter has been used in hypothesis testing e.g age difference parameter.

\section{Hypotheses}

One hypothesis has been formulated in line with the objective

\section{Hypothesis}

Ho: Heat discomfort index does vary significantly among the different age categories in the area.

Hi: Heat discomfort index varies significantly among the different age categories in the area.

\section{Review of related literature}

\section{General overview}

Gleaned from the background and problem statement, a glaring conclusion may be reached that city centres such as Calabar produces higher temperature regimes than the surrounding country side. Supportive of this argument is an earlier field investigation carried by the author (2015 - lead author) which lead to the production of the urban heat mosaic map for the city. The mosaic map showed a clear indication of the dichotomy between the temperature of the inner city area and that of the suburb. A value of $4^{\circ} \mathrm{c}$ was established as the gross mean difference. Ifahimehine (2001), equally investigated the urban heat island phenomenon in the city of Lokoja, Nigeria and equally reported a value of $5^{\circ \mathrm{c}}$ difference between the city centre and that of the periphery.

Ifeluwa, Ahmed, Zachariah (2011) investigated the urban heat island characteristics in the city of Akure, Nigeria. Several parameters were explored by them in respect of the heat island characteristics. Their results revealed clear distinctions in the heat Island regimes on spatial, temporal and landscapes/landcover basis, On the merits representative findings information on urban heat studies on tropical cities is scanty compared to the city of developed countries.

A particular finding that lend credence to this proposed research endeavour is that conducted by Balogun and Balogun (2014) on "Urban Heat Island and Bioclimatic conditions in Hot Humid Tropical City, Akure Nigeria. Their focus in this study was the establishment of links between urban heat development or incidence 
and the index of human discomfort which may produce heat stress or health risks. Their approach employed the basis of "urbanization influenced on bioclimatic conditions of Akure" using the simple thermohygrometric index (THI). Discomfort Index (DI), and the Relative Strain Index (RSI). Simply explained, these indices are;

- THI (Temperature relative Humidity Index)

- DI (Index of human skin discomfort) and

- RSI (Individual response discomfort).

The validity of the use of these indices stems from the environmental/ecological considerations of the area of study. Hence the tropical location of the city of Akure Nigeria. The results derived from these findings revealed significant difference in the three parameters on spatial and temporal basis. In general, torrid (very hot) conditions prevail on nocturnal basis and seasonal basis but extremes have not been identified to warrant clinical conditions of the human health discomfort in the area.

\section{Urban Bioclimatalogical Effect on Human Health}

Urban bioclimatic response refers to human psychosomatic stimulus response to the incidence of urban heat warming (Balogun and Balogun 2014). Such response is the result of adverse health impact of the thermodynamic change occurring in the urban canopy layer (Gray and Fisher 2002). Numerous investigation have been carried out in this direction. The findings revealed a significant high impact levels on human residents in several city domains the world over.

Accordingly, Marsh and Grossa (2002) have provided tangible evidence in line will) above position; They reported that in the United States, within a span of 30 years, over 10,000 persons have died from a particular heat related disease called "Heat Syndrome". They said heat syndrome relates to several clinical recognized disorder in the heat regulatory system of the human body. It is ascribed to several related causative factors; Report was also provided concerning incidence of heat waves in St. Fouis Missouri where large death tools were reported (Marsh and Grossa, 2008).

In their investigation of heat acclimation of residents in Pretoria, South Africa, Maymes, Buskirk and Huodson (2004) identified heat tolerance difference between persons of lean body size and those with obese physiology and discovered that persons -with lean body sizes are less susceptible to heat discomfort than those with amorphous body sizes. Again the above scholars investigated acclimation based on heat exposure and found several interesting results. First, it was discovered that there was a direct correlation between body size and the response of women to heat stress. They concluded that people with different physical body conditions acclimate to the heat stress at different rates. Other parameters related to heat acclimation rate included differences in rectal temperature, changes in heart beat rates, changes in sweat and metabolic rate among others.

An NOAA study (1995) reported that Women generally are better at heat acclimation than men because they perspire less and they lose less salt than men. Investigation have also been conducted on heat prevalence and its impact on human productivity generally. On the general note, thermal influence on human activity has been clearly substantiated in several literatures Allen (2008) and Hen, (2012). In these studies evidence have been provided to support the view that extreme weather trends generally retard human productive capacities. Extremely high (torrid) tropical heat enervates (saps) energy and retards human productivity and on the other hand, extremely low winter weather regimes depresses the spirit and inhibits activities.

\section{Vulnerability/adaptation and mitigation of heat urban stress}

Heat vulnerability explains the extent of individual susceptibility to urban heat stress (Allen 2008). Vulnerability assessment in-cooperate essence of individual coping strategy to heat impact systems. Vulnerability under Inter Governmental Panel on Climate Change (IPCC, 2007) has been defined using several parameters some of which are climatic while others are non-climatic. Relating to the climate change and related socio-economic factors. Conception of some scholars have provided a new bent to IPCC's assessment of review. 
Hence, Dilley and Booker (2001) stated that "vulnerability is the degree to which a system is susceptible or unable to cope with adverse effects of climate change including climate variability and extremes". Thus, vulnerability is a function of the character, magnitude and the rate of climate variation to which a system is exposed to it. In our endeavour, climate variability which rightly captures the essence of urban heat island incidence gives direction to our purpose of the study. Heat stress bioclimatic index has both climatic and nonclimatic implications to its vulnerability conception.

Economic considerations relate to individual socio-economic status which is significant in explanation of the coping strategies among individuals in the urban development, to landscape, water and air pollution from industrial and other sources etc. This study therefore forms part of any other attempt to -investigate the health status of urban residents in the domain of Bioclimatology.

Actuarians or health statisticians demand enormous knowledge from a study of this nature in order to adequately provide information on the basis of urban epidemiology. Urban 1 Environmental images are variegated in the sense that human activity types vary from one domain to other. This study focuses on mitigation of the overall process of "urban browning" with information or findings derived from this study, green development planning can. be actualized to ameliorate the intensity of urban thermal effect.

\section{Research methodology}

\section{- Research Procedures}

This research design is a field survey design requiring insitu data collection from the field involving both biophysical and socio-cultural data. These categories of data will provide baseline information on which the overall investigation will be premised.

Biophysical information will require data capturing on urban heat mosaic across the entire city landscapes. Social cultural data will concern identification of the various categories of urban residents according to residential quality assessment, socio economic status etc.

The third step in the research procedure will involve field reconnaissance - survey aimed at designating the city landscape into city blocks based on land use categories and activity type in the domain.

The fourth step involves training and induction of field research assistants and the organization of the general field logistic support.

The fifth stage involves development of field data collection instruments (Questionnaire, Checklist etc), purchase of instruments and equipments such as maps, Global Positioning system, thermometers, etc.

Finally, field data collection which would be carried out in two phases e.g. dry season phase and wet season phase.

\section{- Instruments for Data Collection}

The instruments needed for field data collection included the following:

- Thermometers for heat data capturing

- Stevenson screen for housing thermometers. -

- Global positioning System (GPS)

- Field Landuse/Land cover maps.

- Questionnaires and checklists.

- Miscellaneous -Tape Measure, notebooks, pens, stereoscopes etc.

\section{- Research Population}

Two categories of population have be employed in this research.

- Biophysical parameters - Landscape, Land cover type, 1-leat Mosaic clusters etc.

- Socio-cultural population - Urban residents e.g. adult male and female, boys and girls of school age etc.

\section{- Data Sampling}


Sampling techniques and strategies involved multi-stage sampling such as:

- Purposive sampling involving selection and designation of urban landscape landcover clusters.

- Stratified sampling based on categorization of residents based on sex, age, socioeconomic status and so on.

- Random sampling based on drawing representative samples from each category of population stratum.

- Data analysis

- Parametric statistics for purposes of hypothesis testing was applied for decision making in. line with the data characteristics or type. Favoured techniques involved chi-square and analysis of variance (ANOVA)

\section{Data presentation and analysis}

Data presentation

The field data acquired were presented in tables as follows.

Table 1: Resident Discomfort rating in overall stu4y' area, Calabar Nigeria.

\begin{tabular}{|c|c|c|c|c|c|c|c|c|c|}
\hline $\mathbf{S} / \mathbf{N}$ & $\begin{array}{l}\text { ITEMS RESPONSE } \\
\text { CATEGORIES }\end{array}$ & & $\begin{array}{r}\text { TIN } \\
\mathrm{S}\end{array}$ & $\begin{array}{l}\text { SCA } \\
\mathbf{X}\end{array}$ & & & & TOTAL & dff \\
\hline & & $\mathbf{A}$ & SA & D & SD & MALE & FEMALE & & \\
\hline 1 & $\begin{array}{l}\text { Effect of high heat incidence } \\
\text { on residence }\end{array}$ & 550 & 225 & 85 & 40 & 450 & 450 & 900 & 00 \\
\hline 2 & Effect of heat on physical body & 300 & 206 & 104 & 285 & 440 & 445 & 895 & 05 \\
\hline 3 & Effect on emotion & 320 & 240 & 125 & 100 & 380 & 425 & 805 & 45 \\
\hline 4. & Effect on mentality & 415 & 230 & 83 & 40 & 420 & 388 & 808 & 32 \\
\hline 5 & $\begin{array}{l}\text { Heat incidence causes in your } \\
\text { nusea or dissizeness }\end{array}$ & 475 & 320 & 65 & 30 & 440 & 450 & 890 & 50 \\
\hline 6 & $\begin{array}{l}\text { Effect on reduction on } \\
\text { productivity }\end{array}$ & 408 & 303 & 80 & 4 & 445 & 450 & 895 & 05 \\
\hline 7 & $\begin{array}{l}\text { Heat impact affect your level of } \\
\text { sleep }\end{array}$ & 483 & 307 & 06 & 00 & 450 & 446 & 896 & 04 \\
\hline 8 & $\begin{array}{l}\text { Developed heat rashes during } \\
\text { heat period of intense heats }\end{array}$ & 499 & 205 & 64 & 102 & 395 & 415 & 810 & 20 \\
\hline 9 & Effect on renal elements & 520 & 210 & 80 & 62 & 432 & 440 & 872 & 08 \\
\hline 10 & Effect on mood change & 466 & 345 & 84 & 04 & 442 & 447 & 899 & 05 \\
\hline
\end{tabular}

From the table above a total of nine hundred respondents were randomly drown/sampled for the respondents interview. One hundred and fifty respondents were drawn from each of these selected clusters. Male and female respondents were drawn at equal ration of 1:1 variation is experienced where data administration is achieved $100 \%$. 
Table 2: Discomfort index of persons of age brackets of 6-21 years

\begin{tabular}{rllllll}
\hline S/NO & ITEMS RESPONSE & A & SA & D & SA & TOTAL \\
\hline 1. & Effect of high heat incidence on residence & 108 & 120 & 40 & 22 & 290 \\
\hline 2. & Effect of heat on physical body & 105 & 115 & 50 & 32 & 302 \\
\hline 3. & Effect on emotion & 88 & 94 & 72 & 43 & 297 \\
\hline 4. & Effect on mentality & 89 & 96 & 65 & 60 & 310 \\
\hline $\mathbf{5 .}$ & $\begin{array}{l}\text { Heat incidence causes in your nusea or } \\
\text { dissizeness }\end{array}$ & 72 & 79 & 68 & 46 & 265 \\
\hline 6. & Effect on reduction on productivity & 105 & 109 & 44 & 34 & 292 \\
\hline 7. & Heat impact affect your level of sleep & 122 & 101 & 48 & 21 & 292 \\
\hline 8. & $\begin{array}{l}\text { Developed heat rashes during heat period of } \\
\text { intense heats }\end{array}$ & 125 & 92 & 61 & 10 & 288 \\
\hline 9. & Effect on renal elements & 132 & 98 & 46 & 21 & 299 \\
\hline 10. & Effect on mood change & 85 & 89 & 72 & 46 & 292 \\
\hline
\end{tabular}

Analysis of table 3: ANOVA of Heat discomfort index among the different age categories in the area

\begin{tabular}{lllll}
\hline Variable SOURCE & df & DS & MS & F-ratio \\
\hline Treatment & 3 & 305.125 & 101.708 & \\
Error & 36 & 428.25 & 1177.382 & 0.09464 \\
Total & 39 & 42640.375 & & \\
\hline
\end{tabular}

*Significant at .05

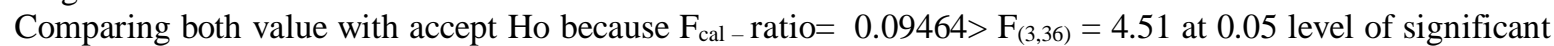
and we conclude that there is no heat discomfort index does not varies significantly among the different age categories in the area.

Table 4: Discomfort index of persons of age brackets of 22-50 years

\begin{tabular}{|r|l|l|l|l|l|l|}
\hline S/NO & ITEMS RESPONSE & A & SA & D & SA & TOTAL \\
\hline $\mathbf{1 .}$ & $\begin{array}{l}\text { Effect of high heat incidence on } \\
\text { residence }\end{array}$ & 108 & 105 & 60 & 25 & 299 \\
\hline $\mathbf{2 .}$ & Effect of heat on physical body & 118 & 96 & 54 & 35 & 303 \\
\hline $\mathbf{3 .}$ & Effect on emotion & 120 & 115 & 46 & 16 & 297 \\
\hline $\mathbf{4 .}$ & Effect on mentality & 125 & 128 & 25 & 21 & 299 \\
\hline $\mathbf{5 .}$ & $\begin{array}{l}\text { Heat incidence causes in your } \\
\text { nausea or dissizeness }\end{array}$ & 129 & 105 & 38 & 20 & 292 \\
\hline $\mathbf{6 .}$ & $\begin{array}{l}\text { Effect on reduction on } \\
\text { productivity }\end{array}$ & 114 & 108 & 47 & 22 & 291 \\
\hline $\mathbf{7 .}$ & $\begin{array}{l}\text { Heat impact effect your level of } \\
\text { sleep }\end{array}$ & 121 & 110 & 48 & 20 & 290 \\
\hline $\mathbf{8 .}$ & Developed heat rashes during heat & 100 & 121 & 49 & 20 & 290 \\
\hline
\end{tabular}




\begin{tabular}{|l|l|l|l|l|l|l|}
\hline & period of intense heats & & & & & \\
\hline 9. & Effect on renal elements & 85 & 89 & 65 & 41 & 280 \\
\hline 10. & Effect on mood change & 108 & 111 & 49 & 30 & 200 \\
\hline
\end{tabular}

Analysis of table 5: ANOVA of Heat discomfort index of persons of age brackets of 50 years old and above

\begin{tabular}{lllll}
\hline Variable SOURCE & df & DS & MS & F-ratio \\
\hline Treatment & 3 & 1857.228 & 619.075 & \\
Error & 36 & 31667.75 & 879.687 & 0.7937 \\
Total & 39 & 33524.975 & & \\
\hline
\end{tabular}

*Significant at .05

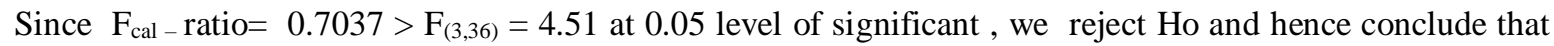
there is significant different between heat discomfort index of persons of age brackets of 50 years old and above.

\section{Discussion of findings}

The overall result of the study was quiet conformal with on earlier finding by Balogun and Bologun (2014) in the urban bioclimatic discomfort of Akure Nigeria where these scholars reported that torrid or very hot conditions prevail on seasonal bases but extremes have not been identified to arrange clinical conditions of the human health discomfort in the area. This report negates the reports of the earlier findings of studies on some carrier cites of developed world areas. In particular, marsh Grossa's (2002) report on united state cities stand in high contradistinction from the general report of this work and earlier findings of Balogun and Bologun (2014) as reported by the marsh and Grossa (2002) 'in the united states over a period of 30year more than 10,000 person died from a particular heat related diseases called heat syndrome.

Ideally, tropical cities are supposed to develop. Lethal heat effects but the factor of city size may also come to play in the explanation of absence of extreme heat development warranting clinical condition as well as other ameliorating parameters as open space between present of urban green areas, less development of urban tarmal concrete surfaces etc. Hence the nitty, gritty of this research resolves as follows.

The tables employed for the analysis of variance conveyed information about two age categories of population in the area. The first table conveyed responses provided by residents with in the age brackets of 621 years of age. The result of ANOVA testing produce the verdict leading to the injection of $\mathrm{HI}$ and the acceptance of HO: this implies that there is no significant difference in the heat bioclimatic effect of persons of this age category Inference may draw based on the number of related explanation

- The homogenous nature of the population may be the reason for the non-significant difference in the response

- Environmental considerations may also come to play in the area of landscape/landcover of the area covered by the study and other ecological ameliorants.

The second table conveying responses or information of age categories 22-50 years yielded an opposite result from the first. Here following the F-ratio $=0.7033<+\left(3,36=4.51\right.$ at 0.05 level of significance, $\mathrm{H}_{\mathrm{O}}$ was rejected and $\mathrm{H}_{\mathrm{I}}$ accepted. This means that there is a significance difference in the heat bioclimatic effect the respondents in the study area. This many border on visceral and phenotypic composition of the individual. Evidently prodigious literature exist in support of the co-connection between bioclimatic susceptibility and chronological age of each individual. Thermal sensitivity generally has been recognized to be in linear 
relationship with chronological age (Watson 2007). This is in line with Relative Strain Index (RSI) a varant of the thermal discomfort index

This appeal to essence of differences in heat or thermal sensitivity generally.

Like in previous findings, the result of this study is party conformal and party non conformal to some existing theories. it has also been established that heat susceptibility is less impacting than thermal cold variability. In this cause people survive more in extreme heat conditions than in apposite conditions of chilliness.

\section{Conclusion}

Urban heat microclimate evidences have been well proven by several investigation in the field. Currently, the present scenario of climate change and global warming have exacerbated heat island effect on most central city areas in different parts of the world. The heat incident effect is more devastating in developed world cities as result of sprawling formation of conurbations or of megalopolis. Anthropogenic activities in such areas as industries, urban development, urban transportation and other similar activities have led to the aggravation of the heat incident in developed world regions causing large death tolls through heat stroke and heart syndrome, in the cities of developing world regions such as Calabar, human activities scope and the scale of urbanization are far less compared to of USA and similar to others areas. This may has explain the relatives less severity of the heat discomfort based on findings drawn from the result of this research. 


\section{Appendix 1}

Questionnaire for data collection on heat Bioclimatic index of resident in Calabar, Cross River State, Nigeria.

Dear respondent.

Please respond to the items provided by choosing an option of your choice based on the four point creating skills providing below.

A AGREE, SA Strongly Agree, D DIS AGREE, SD Strongly Disagree.

1. Do you experience high incidence of heat your area of residence
A [ ] SA [ ] D [ ] SD [ ]

2. Does heat effect affect your physical body energy, A [ ] SA [ ] D [ ] SD [ ]

3. Does heat effect disturb your emotional stability? A [ ] SA [ ] D [ ] SD [ ]

4. Does heat incident cause mental disturb ant in your body system A [ ] SA [ ] D [ ] SD [ ]

5. Does heat incidence cases in your nusea or dissizeness A [ ] SA [ ] D [ ] SD [ ]

6. Does Heat impact reduce your productivity level in work A [ ] SA [ ] D [ ] SD [ ]

7. Does heat impact affect your level of sleep A [ ] SA [ ] D [ ] SD [ ]

8. Do you Developed heat rashes during heat period of intense heats A [ ] SA [ ] D [ ] SD [ ]

9. How Good is your mental coordination during periods of intense heat incidence ] $\mathrm{D}[\mathrm{SD}[\mathrm{]}$

10. Does heat effect affect your mood A [ ] SA [ ] D [ ] SD [ ] 


\section{References}

Allen, I.E 2008. Relative influence of Urban Climate on outdoor human energy boudget temperature modeling int. Journal of Biometry.28,2-25

Balogun and Balogun 2014. Urban Heat Island and Bio-climatologically condition in hot humid tropical city, the example of Akure, Nigeria. Journal of Geographical society of Berlin. 145 (1-2)

Bonan, G.B. 2002. Ecological Climatology Cambridge University press.

Bursirth, I.E. Hudson G.E. 2004. A Model of human thermal comfort and associated thermal pattern for united states. Publication of climatology xxxi(3)

Cunningha R.W. and Saigo W.B. 2002. Environmental Science: Aglobal concern, Boston, McgrawnHil.

Dilley, A.M. and Booker N.E (2001) Environmental problem in third world cities New York, earth scan psuheatron.

Fien, J. I. Hymes, F. M. and Buskirk 1995.Effects of daily and intermitten Exposure on-Heat acclimation of women.International Journal of Biometeorology 19 (1), 41-52.

Gray, K. A. and Fisher, M. E. 2002.“The Urban Heat Island Photo Chemical Song and Chicago Local features of the problem". Atmospheric pollution prevention division of United states Environmental Protection Agency (USEPA).

Hein, 2012. Urbanization and its effects in the US Climatic record. J. Climatology 3, 125-35

Ifatirnehine, O. 2001. An Assessment of urban-Heat Island of Lokoja and Surrounding using LANDSAT ETM DATA department of Geography and planning Kogi State University.

Ifelewa, A. B.;Ahmed, A. B. and Zacharia, D. A. (2011). Effects of city Size on Adult Bio Climatic Tropical summer nocturnal weather. International Journal of Biom eteorology 24(4).Geology Department of University of Vancouver, British Columbia, Canaola.

Intergovernmental Panel on Climate Change (IPCC 2007). Climatic change impact study First Group Assemnet report. UNEP Climate change Review, Nairobi Kenya.

March and Grossa 2002. Climate Change, London, Cambridge University Press, On global influence of man on climate change.

Means, I: O. 1993. Implications of Global warming Variability and the occurrence of Extreme Climate events. In drought assessment, management planning. Theory and case studies, D. A. Willite Ed.

NOAA 1995. The Oceanographic and Atmospheric Administration, U.S. Agency for monitoring and forecasting, United States Environmental Protection Agency (USEPA)

Ofamata,.G. 1975. Nigeria in Maps, Eastern States.Benin City, Ethiope Publications.

Picket et al. 2001. In fatimchin O.O an assessment of Urban heat its surrounding using handset ETM data.

Upla, J. I. 2015. Landscape Implications of Urban Heat Island Phenomenon in Calabar. A Ph.D thesis Dissertation Submitted to the Department of Geography and Environmental Science, University of Calabar, Cross River State, Nigeria.

Yoslokaid, A.B, A Tsuchio, M.M. 1996. Urban Heat Island and Urban Health Early American Perspectives. Professional Geographers, 43(1) 38-48

Zhoa and Wag 2002.The Urban climate.Academic press. New York 6 